\title{
Cardiovascular disease (CVD) and associated risk factors among older adults in six low-and middle-income countries: results from SAGE Wave 1
}

Ye Ruan ${ }^{1 \dagger}$, Yanfei Guo ${ }^{1 \dagger}$, Yang Zheng ${ }^{1}$, Zhezhou Huang ${ }^{1}$, Shuangyuan Sun ${ }^{1}$, Paul Kowal ${ }^{2,3}$, Yan Shi ${ }^{1^{*}}$ and Fan Wu ${ }^{1 *}$

\begin{abstract}
Background: Cardiovascular disease (CVD) is one of the leading causes of death worldwide. Our study aimed to investigate the prevalence of two conditions, angina and stroke, and relevant risk factors among older adults in six low- and middle- income countries(LMICS).

Methods: The data was from World Health Organization (WHO) Study on global AGEing and adult Health (SAGE) Wave 1 in China, Ghana, India, Mexico, Russian Federation and South Africa. Presence of CVD was based on self-report of angina and stroke. Multivariate logistic regression was performed to examine the relationship between CVD and selected variables, including age, sex, urban/rural setting, household wealth, and risk factors such as smoking, alcohol drinking, fruit/vegetable intake, physical activity and BMI.

Results: The age standardized prevalence of angina ranged from $9.5 \%$ (South Africa) to $47.5 \%$ (Russian Federation), and for stoke from 2.0\% (India) to 6.1 \% (Russia). Hypertension was associated with angina in China, India and Russian Federation after adjustment for age, sex, urban/rural setting, education and marital status (OR ranging from 1.3 [1.1-1.6] in India to 3.8 [2.9-5.0] in Russian Federation), furthermore it was a risk factor of stroke in five countries except Mexico. Low or moderate physical activity were also associated with angina in China, and were also strongly associated with stroke in all countries except Ghana and India. Obesity had a stronger association with angina in Russian Federation and China(ORs were 1.5[1.1-2.0] and 1.2 [1.0-1.5] respectively), and increased the risk of stroke in China. Smoking was associated with angina in India and South Africa(ORs were 1.6[1.0-2.4] and 2.1 [1.2-3.6] respectively ), and was also a risk factor of stroke in South Africa. We observed a stronger association between frequent heavy drinking and stroke in India. Household income was associated with reduced odds of angina in China, India and Russian Federation, however higher household income was a risk factor of angina in South Africa.
\end{abstract}

Conclusion: While the specific mix of risk factors contribute to disease prevalence in different ways in these six countries - they should all be targeted in multi-sectoral efforts to reduce the high burden of CVD in today's society.

Keywords: Cardiovascular diseases, Prevalence, Risk Factors, Low and middle income countries

\footnotetext{
* Correspondence: shiyan@scdc.sh.cn; Wufan@scdc.sh.cn

${ }^{\dagger}$ Ye Ruan and Yanfei Guo contributed equally to this work.

${ }^{1}$ Shanghai Municipal Center for Disease Control and Prevention (Shanghai

CDC), Shanghai, China

Full list of author information is available at the end of the article
}

(c) The Author(s). 2018 Open Access This article is distributed under the terms of the Creative Commons Attribution 4.0 International License (http://creativecommons.org/licenses/by/4.0/), which permits unrestricted use, distribution, and reproduction in any medium, provided you give appropriate credit to the original author(s) and the source, provide a link to the Creative Commons license, and indicate if changes were made. The Creative Commons Public Domain Dedication waiver (http://creativecommons.org/publicdomain/zero/1.0/) applies to the data made available in this article, unless otherwise stated. 


\section{Background}

Cardiovascular diseases (CVDs) are by far the leading cause of death in the world. An estimated 17.9 million people died from CVDs in 2015. Ischemic heart disease (IHD) and stroke were the top two leading causes of CVD health lost in each world region [1, 2]. By 2030 more than 22.2 million people will die annually from CVDs. Populations in low and middle income countries (LMICs) now contribute $75 \%$ of the CVD deaths, which leads to $7 \%$ reduction of gross domestic product(GDP) in these countries [3].

A larger proportion of the global burden of CVDs is now borne by LMICs than in high income countries, this is despite a comparatively lower burden from risk factors in low compared to high income countries [4-6]. Given the high prevalence of CVD among older adults in LMIC, the projected increases in this population will be a major challenge for the health care system. Twenty-three percent of the total global burden of disease(GBD) was attributed to disorders in people aged 60 years and older. The main contributors to disease burden were CVDs, accounting for $30.3 \%$ of the total burden in older people in 2010 [7]. Reliable and comparable analysis of risks to CVD is especially important for projecting future disease burden and for shaping disease prevention efforts.

A number of population-based studies from lower income countries have suggested that socio-demographic characteristics are associated with CVD, with increasing age, female sex and lower education consistently associated with higher prevalence of CVD. Some epidemiological evidence also suggests that CVD is associated with behavioral risk factors such as smoking, alcohol use, low physical activity levels, and insufficient vegetable and fruit intake, hypertension is also regarded as a very important risk factor for CVD. Independently or in combination, these risk factors present an opportunity for interventions to reduce future CVD burdens in ageing populations in LMIC.A number of large recent studies have compared CVD risks in higher and lower income countries, providing valuable and needed information about CVD and CVD risks [4-6]. However, the results of these studies may not be representative of the older adult population. For example, the Prospective Urban Rural Epidemiology (PURE) study sampling strategy and distributions provide less reliable estimates at older ages [8]. The World Health Organization Study on global AGEing and adult health (SAGE) is focused on older adults and use similar methodology across countries to improve comparability of important covariates and disease prevalence. Three of the countries overlap in PURE and SAGE (China, India and South Africa) where SAGE includes three additional middle income countries (Ghana, Mexico and the Russian Federation).
The aim of the present study was to investigate the prevalence of two main CVDs (angina, stroke) and behavioural risk factors and associated social-economic status (SES) factors among older adults using a unique data set with nationally representative samples in six low and middle income countries.

\section{Methods}

\section{Sample and procedure}

The data was from World Health Organization (WHO) Study on Global AGEing and adult health (SAGE) Wave 1 , a longitudinal cohort study of ageing and older adults from 2007 to 2010 in six low- and middle-income countries (China, Ghana, India, Mexico, Russian Federation and South Africa) [9]. SAGE Wave 1 used face-to-face individual interviews to capture data. All six countries implemented multistage cluster sampling strategies which resulted in nationally representative cohorts of older adults (http://www.who.int/healthinfo/sage/SAGEWorkingPaper5_Wave1Sampling.pdf?ua=1). Response rates for SAGE countries were Mexico 51\%, India 68\%, Ghana $80 \%$, Russian Federation 83\%, South Africa $77 \%$ and China 93\%. Examination of non-respondent data suggested non-significant differences on some covariates (data not shown). Data were obtained following application for access through http://apps.who.int/healthinfo/ systems/surveydata/index.php/catalog.

SAGE has been approved by the World Health Organization's Ethical Review Board. Additionally, each partner organization obtained ethical clearance through their respective review bodies. All study participants signed informed consent.

\section{Measures \\ CVDs conditions}

Two methods of assessing presence or absence of CVD were used. One was based on self-report of angina or stroke; and the second used an algorithm based on validated symptom-reporting methods to estimate and compare prevalence rates.

\section{Sociodemographic variables}

Socio-demographic variables contain age, sex, education, rural/urban residence, and income quintiles. Age was categorized into four groups: 50 to 59 years; 60 to 69 years; 70 to 79 years; and 80 years or older. Education level was classified into seven categories for analysis using an international classification scheme [10]. The income quintiles were generated using an asset-based approach- possession of assets and dwelling characteristics [11], with quintile $1(\mathrm{Q} 1)$ the quintile of the poorest households and quintile $5(\mathrm{Q} 5)$ the quintile of the richest. 


\section{Risk factors}

Tobacco use Tobacco use was assessed by self-report and included different forms (manufactured or hand-rolled cigarettes, cigars, cheroots or whether tobacco is smoked, chewed, sucked or inhaled), and frequency of smoking, snuffing or chewing in each day over the week before interview[12], classified into four groups: never smoker, not current smokers, smokers(not daily) and current daily smokers.

Alcohol consumption Alcohol consumption was categorized into four groups: life time abstainer, non-heavy drinkers, infrequent heavy drinkers and frequent heavy drinkers according to the consumption number of standard drinks of beer, wine and or spirit, fermented cider, and other alcoholic drinks during the week before interview.

Physical activity Physical activity was measured by the Global Physical Activity Questionnaire (GPAQ) and assessed intensity, duration, and frequency of physical activity in three domains: occupational, transport-related, and discretionary or leisure time. Based on a standard classification scheme, three categories were generated: low, moderate and high levels [13].

Fruit and vegetable consumption Fruit and vegetable consumption was assessed according to the number of daily servings eaten - with each serving approximating 80 grams. Five or more servings were defined as sufficient daily intake (at least 400 grams per day), fewer than five servings were categorized as insufficient [14].

Hypertension The definition of hypertension used was systolic blood pressure $\geq 140 \mathrm{mmHg}$ and/or diastolic blood pressure $\geq 90 \mathrm{mmHg}$ and/or self-reported treatment with antihypertensive medication during the two weeks before interview. Blood pressure measurements were conducted three times on the right arm of the seated respondent with an automated recording device (OMRON R6 Wrist Blood Pressure Monitor, HEM-6000-E, Omron Healthcare Europe), and calculated as an average of the latter two measurements.

Obesity According to the classification criteria proposed by the WHO [15], body mass index (BMI) of $<18.5 \mathrm{~kg} /$ $\mathrm{m}^{2}, 25-29.9 \mathrm{~kg} / \mathrm{m}^{2}$ and $\geq 30 \mathrm{~kg} / \mathrm{m}^{2}$ are used to define underweight, overweight and obesity, respectively. Modified BMI cutoffs for China and India were used to perform an additional set of analyses that describes overweight (BMI 23.0-27.5) and obesity (BMI >27.5) in Asian populations [16].

\section{Statistical methods}

Statistic analyse were conducted using STATA SE version 11 (Stata Corp, College Station, TX). The prevalence of angina and stroke were calculated by using normalized weights in each country. Weights were based on selection probability, non-response, and post-stratification adjustments. To improve comparability across countries, the prevalence rates were age-standardized using the WHO World Standard Population Distribution based on world average population 2000-2025 [17]. Multivariate logistic regression was performed to examine the relationship between CVD and selected variables, including the socio-demographics such as age, sex, urban/rural setting, education, household wealth, and health risk factors such as smoking, alcohol drinking, fruit/vegetable intake, physical activity, hypertension and obesity. $P<0.05$ from two-sided statistical tests was considered statistically significant.

\section{Results}

A total of 34,114 individuals were included in the final analyses. Table 1 shows the sample distribution and demographic, socioeconomic and lifestyle characteristics by countries. The proportions of women are higher than men in four countries, except Ghana and India. The majority of older Indian lived in rural locations, while compared to urban areas in the other countries. The 50-59 age groups had the largest proportions in all countries, but the SAGE sample population distributions match those of the United Nations and US Census Bureau's International Data Base estimates [18]. The percentage of respondents with no formal education were higher in Ghana (54.0\%) and India (51.2\%). In contrast, Russian Federation had the highest educational level with only $0.5 \%$ with no formal education and over $20 \%$ with a college degree or higher.

The rate of daily smoking ranged from $7.6 \%$ (Ghana) to $46.9 \%$ (India), frequent heavy drinker was the highest in China (6.4\%) and lowest in Mexico (0.1\%), and the highest rate of low physical activity was in South Africa (59.5\%). Insufficient fruit and vegetable intake was more common in India, the Russian Federation and Mexico (90.6, 81.0 and $81.4 \%$, respectively) compared with China, South Africa and Ghana (35.7, 68.5 and 68.9\%, respectively).

The age standardized prevalence of angina ranged from $9.5 \%$ (South Africa) to $47.5 \%$ (Russian Federation). It was higher in women than in men in all six countries. The rates were higher in rural than in urban locations other than in China. Angina rose with age in each country except Mexico, and a slight drop was seen in the highest age group in Ghana, India, Russian Federation and South Africa. The lowest prevalence of angina was found in individuals with the highest household 
Table 1 Sociodemographic characteristics of the study samples, by country (SAGE Wave 1)

\begin{tabular}{|c|c|c|c|c|c|c|c|}
\hline & China & Ghana & India & Mexico & Russian Federation & South Africa & Total \\
\hline Sample size & 13,157 & 4,305 & 6,560 & 2,318 & 3,938 & 3,836 & 34,114 \\
\hline \multicolumn{8}{|l|}{ Gender } \\
\hline Male & 49.8 & 52.4 & 51.0 & 46.8 & 41.9 & 44.1 & 47.2 \\
\hline Female & 50.2 & 47.6 & 49.0 & 53.2 & 58.1 & 55.9 & 52.8 \\
\hline \multicolumn{8}{|l|}{ Residence } \\
\hline Urban & 47.3 & 41.1 & 28.9 & 78.8 & 70.1 & 64.9 & 50.4 \\
\hline Rural & 52.7 & 58.9 & 71.1 & 21.2 & 29.9 & 35.1 & 49.6 \\
\hline \multicolumn{8}{|l|}{ Age Group } \\
\hline $50-59$ & 44.9 & 39.7 & 48.6 & 48.1 & 44.1 & 49.9 & 45.8 \\
\hline $60-69$ & 31.9 & 27.5 & 30.9 & 25.6 & 26.7 & 30.6 & 29.7 \\
\hline $70-79$ & 18.6 & 23.1 & 16.0 & 17.8 & 21.4 & 14.0 & 18.7 \\
\hline $80+$ & 4.6 & 9.7 & 4.5 & 8.6 & 7.7 & 5.5 & 5.8 \\
\hline \multicolumn{8}{|l|}{ Education Level } \\
\hline No formal education & 23.1 & 54.0 & 51.2 & 17.2 & 0.5 & 25.2 & 23.8 \\
\hline Less than primary & 18.9 & 10.4 & 10.0 & 38.4 & 1.2 & 24.0 & 10.1 \\
\hline Primary school completed & 21.0 & 10.9 & 14.8 & 24.0 & 5.3 & 22.4 & 13.5 \\
\hline Secondary school completed & 19.9 & 4.0 & 10.2 & 9.9 & 17.9 & 14.2 & 16.0 \\
\hline High school completed & 12.6 & 17.1 & 8.6 & 2.4 & 54.3 & 8.4 & 26.2 \\
\hline College completed & 4.4 & 3.4 & 3.4 & 5.5 & 20.7 & 3.9 & 9.9 \\
\hline Post graduate degree completed & 0.1 & 0.2 & 1.7 & 2.6 & 0.1 & 1.8 & 0.6 \\
\hline \multicolumn{8}{|l|}{ Income Quintile } \\
\hline Lowest & 16.3 & 18.2 & 18.2 & 15.3 & 13.3 & 20.7 & 15.9 \\
\hline Second & 18.1 & 19.1 & 19.5 & 24.7 & 17.1 & 19.9 & 18.2 \\
\hline Third & 20.5 & 20.5 & 18.8 & 16.8 & 19.6 & 18.2 & 19.6 \\
\hline Fourth & 23.4 & 20.7 & 19.6 & 16.6 & 22.1 & 19.8 & 21.7 \\
\hline Highest & 21.8 & 21.6 & 23.9 & 26.6 & 27.8 & 21.3 & 24.5 \\
\hline \multicolumn{8}{|l|}{ Tobacco use } \\
\hline Never smoker & 64.2 & 75.5 & 45.5 & 60.7 & 65.4 & 67.7 & 59.4 \\
\hline Not current smokers & 6.6 & 14.2 & 4.7 & 19.1 & 13.2 & 9.5 & 8.5 \\
\hline Current smokers, not daily & 2.5 & 2.6 & 2.9 & 6.9 & 2.0 & 3.4 & 2.5 \\
\hline Current smokers, daily & 26.7 & 7.6 & 46.9 & 13.3 & 19.4 & 19.4 & 29.6 \\
\hline \multicolumn{8}{|l|}{ Alcohol } \\
\hline Life time abstainer & 74.2 & 57.8 & 92.5 & 64.3 & 33.7 & 84.5 & 69.8 \\
\hline Non-heavy drinkers & 18.2 & 39.5 & 6.9 & 29.3 & 55.4 & 11.5 & 24.3 \\
\hline Infrequent heavy drinkers & 1.2 & 1.2 & 0.4 & 6.2 & 8.5 & 3.0 & 2.9 \\
\hline Frequent heavy drinkers & 6.4 & 1.5 & 0.2 & 0.1 & 2.5 & 1.0 & 3.0 \\
\hline \multicolumn{8}{|l|}{ Fruit and vegetable intake } \\
\hline Sufficient & 64.3 & 31.1 & 9.4 & 18.6 & 19.0 & 31.5 & 38.1 \\
\hline Insufficient & 35.7 & 68.9 & 90.6 & 81.4 & 81.0 & 68.5 & 61.9 \\
\hline \multicolumn{8}{|l|}{ Physical activity levels } \\
\hline High & 44.4 & 61.7 & 52.3 & 39.6 & 61.7 & 28.2 & 52.5 \\
\hline Moderate & 27.3 & 12.5 & 22.8 & 22.4 & 15.4 & 12.3 & 21.2 \\
\hline Low & 28.3 & 25.8 & 25.0 & 38.0 & 22.9 & 59.5 & 26.3 \\
\hline
\end{tabular}


income in China, Ghana, India and Russian Federation, respectively (see Table 2 ).

The prevalence of stroke was $6.1 \%$ in Russian Federation, which was higher than the other SAGE countries, while India had the lowest prevalence of $2.0 \%$. In Russian Federation, the prevalence of stroke in men was almost twice that of women. Stroke was higher in urban than in rural locations in all six countries. Stroke prevalence tended to increase with age in all SAGE countries, but a slight drop in $80+$ age group in Mexico and Russian Federation. In China, the wealthiest older adults had the lowest stroke prevalence (see Table 3).

Table 4 shows the Odds ratios for likelihood of angina by risk factors. Hypertension was associated with angina in China, India and Russian Federation after adjustment for age, sex, urban/rural setting and education (OR ranging from 1.32 [1.13-1.55] in India to 3.80 [2.91-4.96] in Russian Federation). Low and moderate physical activity was also associated with angina in China (ORs were 1.46 [1.22-1.76] and 1.66[1.39-1.99], respectively). Obesity had a stronger association with angina in Russian Federation and China (ORs were 1.48[1.08-2.02] and 1.24[1.01-1.53], respectively). Smoking was associated with angina in India and South Africa (ORs were 1.56[1.02-2.36] and 2.11 [1.23-3.61], respectively). Non-heavy drinking was a protective factor for angina in China (OR was 0.67[0.51-0.87]). The OR (1.56[1.19-2.05]) for insufficient fruits and vegetables intake was highest in Ghana. Household income was associated with reduced odds ratios of angina in China, India and Russian Federation, however higher household income was a risk factor of angina in South Africa (see Table 4).

In all six LIMCs except Mexico, hypertension was associated with stroke (OR ranging from 1.98[1.04-3.80] in Ghana to 3.16[1.72-5.83] in Russian Federation). Low, moderate physical activity were also strongly associated with stroke in four LMICs apart from Ghana and India. In China, Obesity increased the risk of stroke (OR was 1.66[1.20-2.28]). Smoking was also a risk factor of stroke in South Africa. We observed a stronger association between frequent heavy drinking and stroke in India (OR 6.64[1.39 - 31.82]). Insufficient fruit and vegetable intake and household income were not significantly associated with stroke in any of the countries (see Table 5).

\section{Discussion}

This study reports the prevalence of two common cardiovascular diseases, angina and stroke, and the relevant risk factors among older adults in six LIMCs. Globally, the age-adjusted CVDs mortality continues to be unevenly distributed: where it has decreased in high income countries(HICs) by $43 \%$ in recent decades [19], while LIMCs are drowning in a rising tide of CVD. Although age-standardized rates of death attributable to

Table 2 Prevalence of angina by age, sex, residence and income quintiles among adults aged 50 years and older, by country (SAGE Wave 1)

\begin{tabular}{|c|c|c|c|c|c|c|c|c|c|c|c|c|}
\hline & \multicolumn{2}{|c|}{ China } & \multicolumn{2}{|c|}{ Ghana } & \multicolumn{2}{|l|}{ India } & \multicolumn{2}{|c|}{ Mexico } & \multicolumn{2}{|c|}{ Russian Federation } & \multicolumn{2}{|c|}{ South Africa } \\
\hline & $\%$ & $95 \% \mathrm{Cl}$ & $\%$ & $95 \% \mathrm{Cl}$ & $\%$ & $95 \% \mathrm{Cl}$ & $\%$ & $95 \% \mathrm{Cl}$ & $\%$ & $95 \% \mathrm{Cl}$ & $\%$ & $95 \% \mathrm{Cl}$ \\
\hline Total & 9.9 & {$[8.7,11.2]$} & 13.1 & {$[11.5,14.9]$} & 19.6 & {$[16.5,23.0]$} & 13.9 & {$[8.6,21.6]$} & 47.5 & {$[42.3,52.8]$} & 9.5 & {$[8.5,10.5]$} \\
\hline \multicolumn{13}{|l|}{ Age group } \\
\hline $50-59$ & 5.6 & {$[4.7,6.6]$} & 11.1 & {$[9.1,13.4]$} & 16.1 & {$[13.7,18.7]$} & 17.9 & {$[8.9,32.8]$} & 37.2 & {$[29.5,45.7]$} & 9.1 & {$[7.7,10.6]$} \\
\hline $60-69$ & 10.9 & {$[9.4,12.6]$} & 14.2 & {$[11.9,17.0]$} & 21.3 & {$[16.7,26.7]$} & 9.1 & {$[6.6,12.3]$} & 46.2 & {$[39.2,53.3]$} & 9.8 & {$[8.2,11.7]$} \\
\hline 70-79 & 17.5 & {$[14.7,20.6]$} & 15.2 & {$[12.5,18.4]$} & 26.3 & {$[20.8,32.6]$} & 8.7 & {$[5.6,13.3]$} & 66.1 & {$[57.5,73.8]$} & 10.1 & {$[7.9,12.8]$} \\
\hline $80+$ & 23.1 & {$[18.5,28.4]$} & 12.9 & {$[9.6,17.1]$} & 22.3 & {$[16.3,29.7]$} & 16.1 & {$[8.0,29.5]$} & 56.1 & {$[33.5,76.4]$} & 8.0 & {$[5.1,12.3]$} \\
\hline \multicolumn{13}{|l|}{ Sex } \\
\hline Men & 6.9 & {$[6.0,7.9]$} & 9.8 & {$[8.3,11.6]$} & 16.1 & {$[13.0,19.8]$} & 7.5 & {$[4.9,11.5]$} & 44.6 & {$[36.8,52.6]$} & 7.9 & {$[6.6,9.4]$} \\
\hline Women & 13.1 & {$[11.5,14.9]$} & 16.8 & {$[14.4,19.4]$} & 23.3 & {$[19.7,27.4]$} & 19.5 & {$[10.4,33.7]$} & 49.6 & {$[42.9,56.4]$} & 10.5 & {$[9.3,12.0]$} \\
\hline \multicolumn{13}{|l|}{ Residence } \\
\hline Urban & 12.3 & {$[10.0,14.9]$} & 9.7 & {$[7.7,12.1]$} & 19.5 & {$[11.8,30.5]$} & 13.8 & {$[7.7,23.7]$} & 47.4 & {$[41.8,53.0]$} & 9.0 & {$[7.9,10.2]$} \\
\hline Rural & 8.0 & {$[6.9,9.3]$} & 15.3 & {$[13.1,17.9]$} & 19.6 & {$[17.5,21.9]$} & 14.1 & {$[7.9,23.9]$} & 48.0 & {$[37.0,59.2]$} & 10.3 & {$[8.6,12.2]$} \\
\hline \multicolumn{13}{|c|}{ Income Quintile } \\
\hline Q1 (Lowest) & 11.3 & {$[9.0,14.0]$} & 15.7 & {$[12.4,19.6]$} & 24.9 & {$[19.6,31.1]$} & 19.8 & {$[11.7,31.7]$} & 43.5 & {$[29.9,58.1]$} & 7.6 & {$[5.8,9.8]$} \\
\hline Q2 & 11.3 & {$[9.4,13.5]$} & 14.5 & {$[11.6,18.1]$} & 17.2 & {$[14.0,20.9]$} & 5.6 & {$[3.2,9.8]$} & 58.2 & {$[48.0,67.7]$} & 8.2 & {$[6.4,10.5]$} \\
\hline Q3 & 11.1 & {$[9.3,13.0]$} & 16.0 & {$[12.9,19.6]$} & 23.4 & {$[16.4,32.2]$} & 29.7 & {$[8.3,66.4]$} & 57.3 & {$[42.6,70.8]$} & 11.1 & {$[9.0,13.7]$} \\
\hline Q4 & 8.7 & {$[7.2,10.6]$} & 12.5 & {$[10.0,15.6]$} & 19.1 & {$[14.4,24.7]$} & 11.1 & {$[6.6,17.9]$} & 47.4 & {$[34.6,60.6]$} & 11.5 & {$[9.4,14.1]$} \\
\hline Q5 (Highest) & 8.2 & {$[6.2,10.8]$} & 7.3 & {$[5.5,9.6]$} & 14.8 & {$[12.3,17.8]$} & 10.5 & {$[5.2,20.3]$} & 37.4 & {$[29.8,45.6]$} & 8.8 & {$[6.9,11.0]$} \\
\hline
\end{tabular}


Table 3 Prevalence of stroke by age, sex, residence and income quintiles among adults aged 50 years and older, by country (SAGE Wave 1)

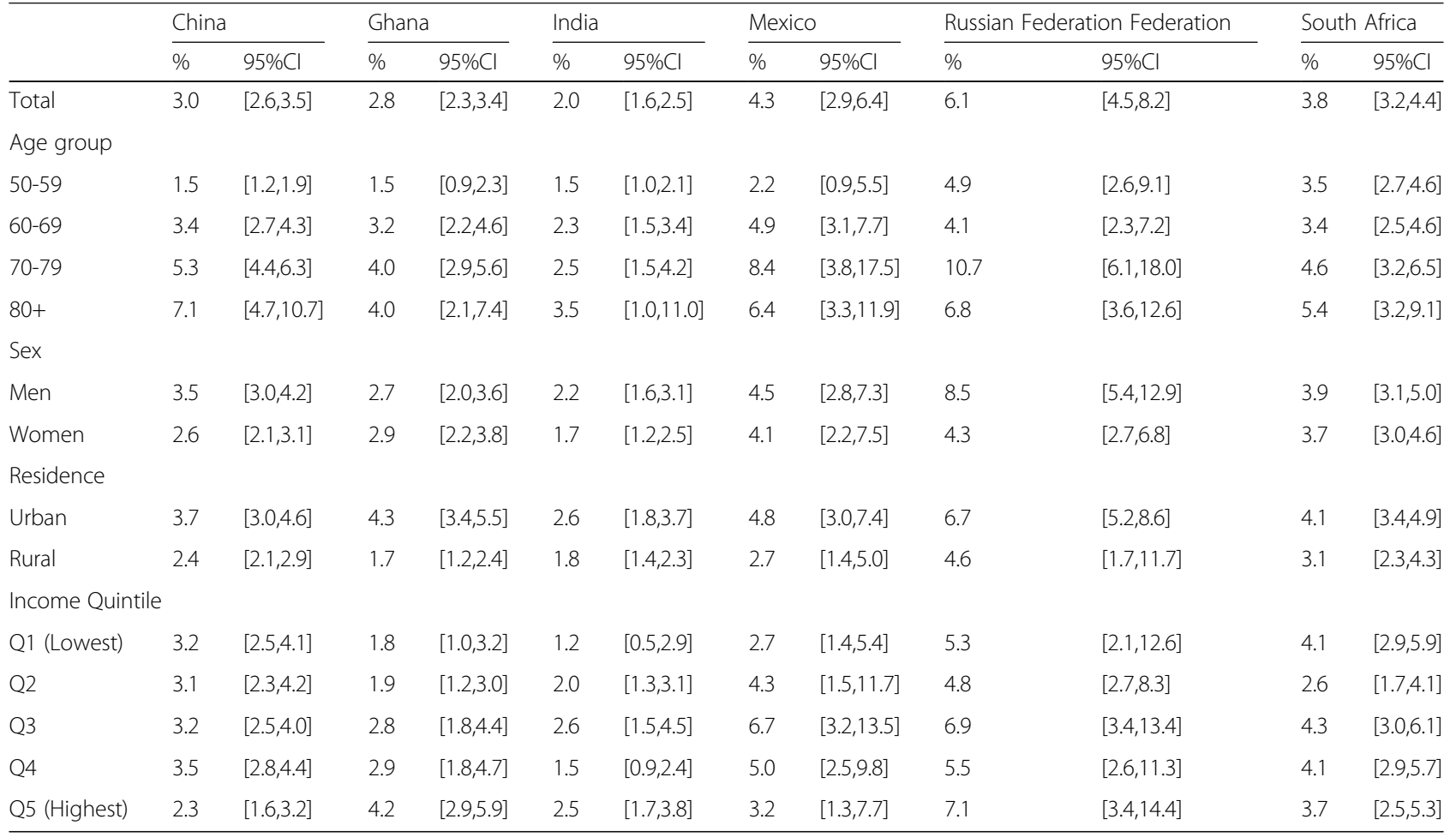

CVD declined 13\% in LMICs from 381 per 100000 in 1990 to 332 per 100000 in 2013, the number of deaths increased 66\% from 7.21 million to 12 million in 2013 with ageing and population growth ascribed as the main drivers [19]. Ischaemic heart disease and cerebrovascular disease (stroke) combined accounted for more than 85.1\% of all cardiovascular disease deaths in 2016[20]. Our study indicated that CVDs(angina, stroke) were prevalent and variable among older adults in six countries. Angina and stroke were both highest in Russian Federation(47.5\%, 6.1\% respectively). Women were more likely to have angina than men in all six countries. Stroke was more prevalent in urban than in rural. Angina and stroke both tended to increase with age in China.

Prevalence of CVDs generally appeared to be most closely linked to a country's stage of epidemiological transition [21], especially when high disease rates in middle age carry through into older ages. Underlying social, environmental, and economic shifts in many countries have led to increasing levels of predominant causes such as tobacco and alcohol use, sedentary lifestyle, unhealthy diets, and suboptimum levels of weight, blood pressure, cholesterol, and plasma glucose. The high and growing prevalence of CVD in LIMCs largely reflects the burden of these key risk factors. Our study revealed that hypertension, high BMI, decreased physical activity, frequent heavy drinking and lower household health were key risk factors of angina and stroke. However, the distribution of risk factors in six counties was unequal, for example, the factor with highest OR of angina in China and Russian Federation was hypertension, whereas it was smoking in India and South Africa.

Hypertension has been shown to be an independent risk factor for acute myocardial infarction and stroke in older people [22, 23]. We found that hypertension was associated with angina in China, India and Russian Federation, in addition it was a risk factor of stroke in five of the six countries in this study (not Mexico). Between 1980 and 2008, blood pressure decreased by $2.0 \mathrm{mmHg}$ or more (for men) and $3.5 \mathrm{mmHg}$ or more (for women) per decade in western Europe and Australia but increased by up to $2.7 \mathrm{mmHg}$ over this same period in Oceania, East and West Africa and South and Southeast Asia [24]. Systematic review revealed that blood pressure lowering greatly reduced the major cardiovascular disease events and all-cause mortality, irrespective of starting blood pressure [25].However among these six LIMCs $66 \%$ hypertensives were undiagnosed before the survey, 73\% untreated and 90\% uncontrolled. Although the proportions of undiagnosed and untreated were lowest in Russia (30\% and 35\%), the uncontrolled rate was higher (83\%) [26], low level of health care (primary and secondary prevention) and irregular treatment continued 


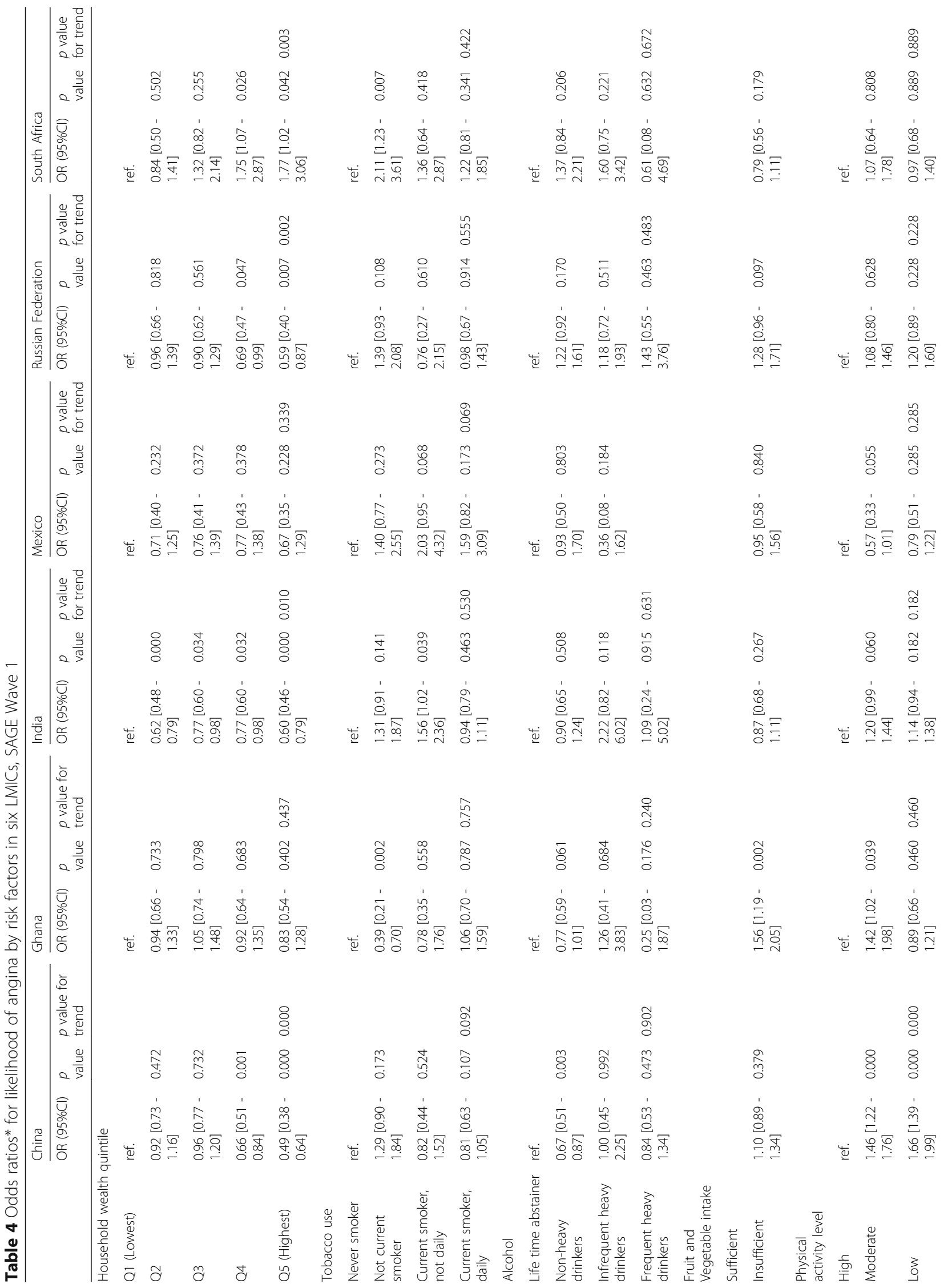




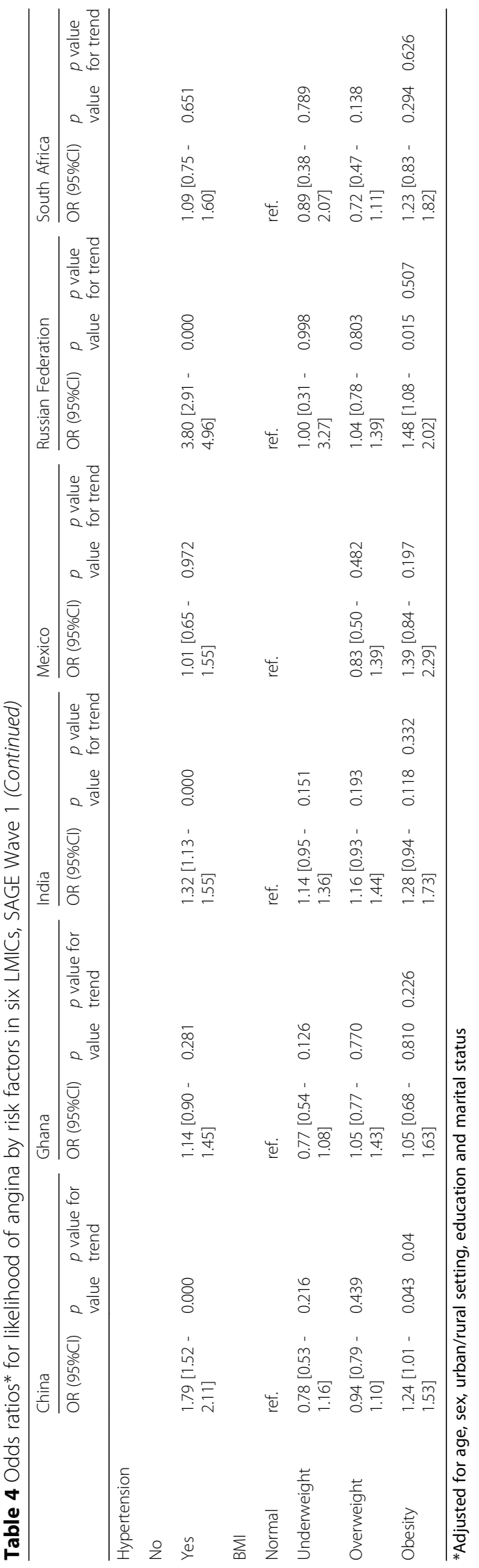




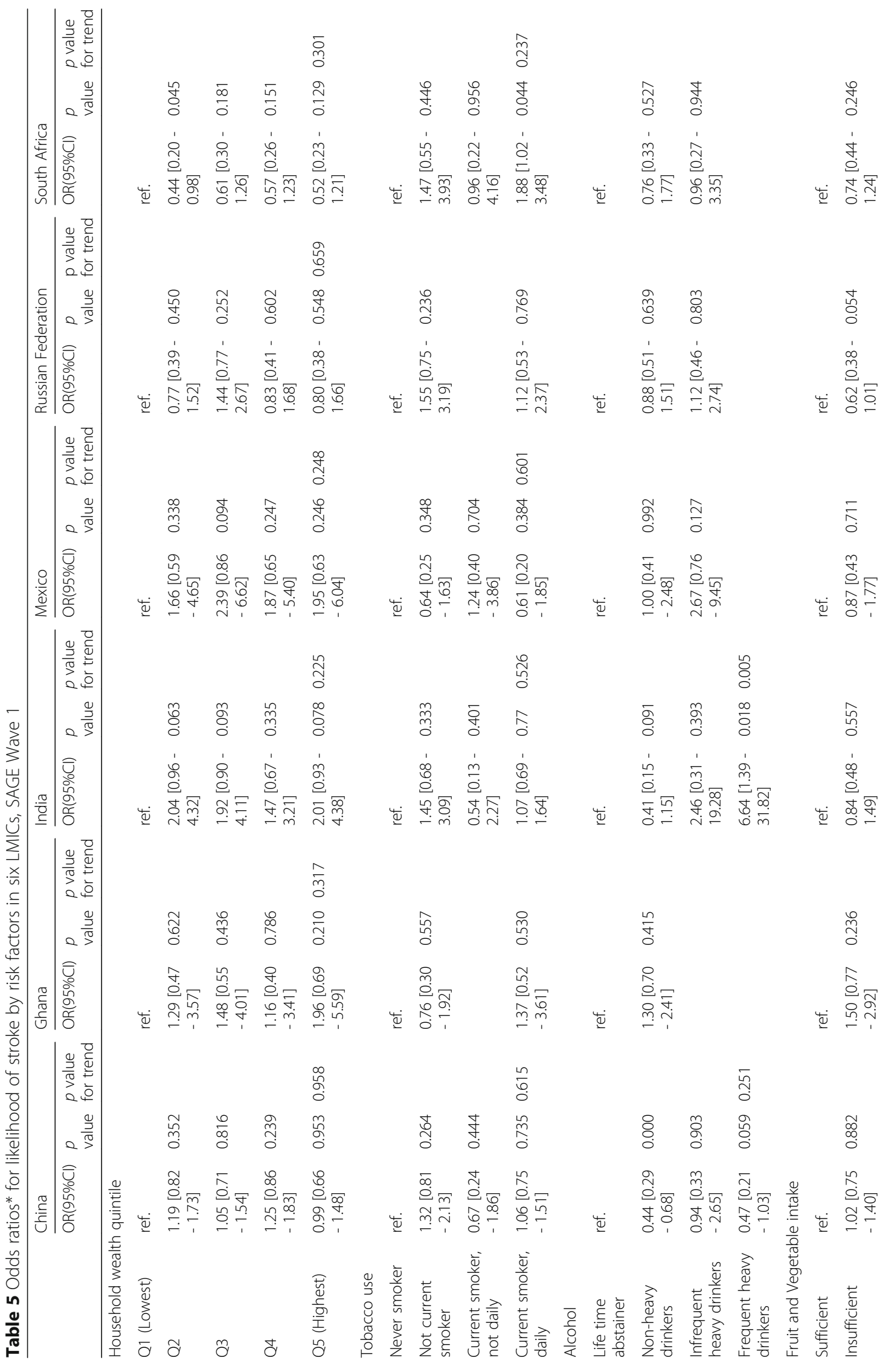




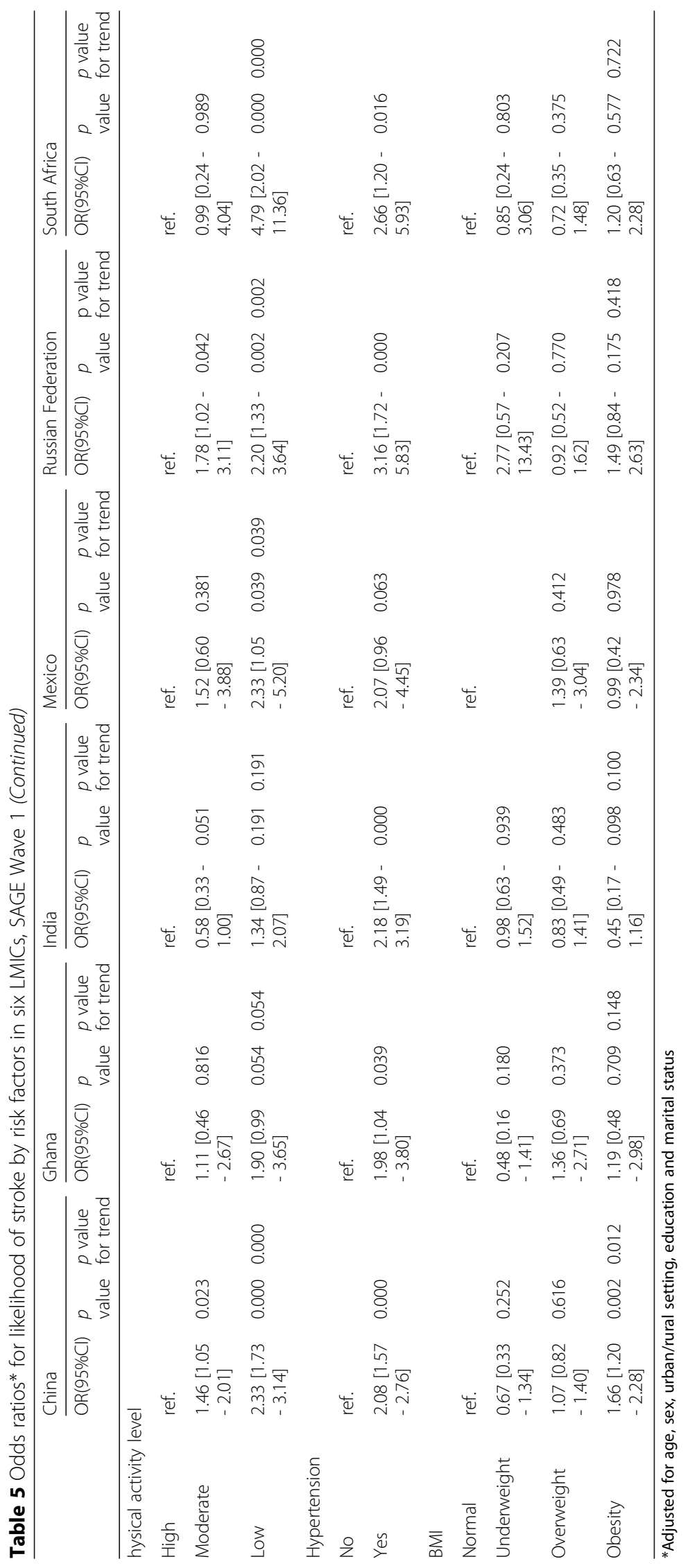


to be a major problem [27]. Hence, further research on early screening strategies, available health care and effective treatment of hypertension may be critical for improving outcomes.

Our study also showed that low physical activity and obesity besides hypertension were both associated with angina and stroke in China, and insufficient fruit and vegetable intake was risk factor of angina in Ghana. Compared with data from 1997, total physical activity in 2009 has decreased by $29 \%$ in males and by $38 \%$ in females in China [28], and physical inactivity was estimated the third leading risk factor for coronary heart disease [29]. As the relation between physical and obesity well recognized, obesity was an important risk factor of CVD. People are becoming more and more obese. Global age-standardised mean BMI increased from 21.7 $\mathrm{kg} / \mathrm{m}^{2}$ in 1975 to $24.2 \mathrm{~kg} / \mathrm{m}^{2}$ in 2014 in men, and from $22.1 \mathrm{~kg} / \mathrm{m}^{2}$ in 1975 to $24.4 \mathrm{~kg} / \mathrm{m}^{2}$ in 2014 in women. Over this period, age-standardised prevalence of obesity increased from $3.2 \%$ in 1975 to $10.8 \%$ in 2014 in men, and from 6.4 to $14.9 \%$ in women [30]. More than $50 \%$ of the obese individuals in the world lived in just 10 countries (listed in order of number of obese individuals): USA, China, India, Russia, Brazil, Mexico, Egypt, Pakistan, Indonesia, and Germany, and China and India jointly accounting for $15 \%$ in 2013[31]. China has moved from 60th place for men and 41st place for women in 1975 to second for both men and women in 2014 in the worldwide ranking of the number of severely obese individuals [30]. Unfortunately, the prevalence of obesity among children and adolescents are both on the rise. In comparison with obesity rate in 1985 , it increased by 8.7 times for children and 38.1 times for adolescents [32]. In the World Health Survey 2002-2003, prevalence of low fruits and vegetable consumption among individuals aged 18-99 years in Ghana was the lowest among 52 countries [33]. However, the prevalence was higher (68.9\%) among persons aged 50 years and older [34]. We also found that insufficient fruits and vegetables intake was associated with angina in Ghana. All of these contribute to the increasing burden of CVD.

We observed a relationship between smoking and angina, frequent heavy drinking and stroke in India. The prevalence of angina was $19.6 \%$ (95\%CI:16.5-23.0) in India, the second highest for these six countries. CVD-related conditions contributed nearly two-thirds of the burden of NCD mortality in India [35], with ischemic heart disease(IHD) and stroke contributing substantially to CVD mortality in India (83\%) [36].Up to $35 \%$ of adults in India consume tobacco [37], with the rate of daily tobacco use was highest $(46.9 \%)$ among the six LIMCs in this study, highest in younger individuals (2035 years) [38].The relation between alcohol consumption and CVD has been widely studied. Several analyses showed that low-moderate levels of alcohol consumption had cardio protective effects, while heavy drinking is harmful, usually described as "U-shaped" or "J-shaped" relationship [39, 40]. Aside from alcohol consumption, drinking pattern (binge-pattern drinking) played an important role in elevating the risk of CVD [41, 42]. Another cohort study showed that heterogeneous associations exist between level of alcohol consumption and CVD: compared with moderate drinking, heavy drinking raised risk of coronary death, heart failure, cardiac arrest, ischaemic stroke but a lower risk of myocardial infarction or stable angina [43]. We found that in China non-heavy drinking was a protective factor for angina and stroke, and frequent heavy drinking showed a dangerous effect for stroke in India.

There were a few limitations in our study. Firstly, although SAGE assembled nationally representative cohorts from six countries, the response rates were different across the countries, ranging from 51\% in Mexico to $93 \%$ in China. The low response rate in Mexico was for specific reasons related to timing of the survey and inability to engage in repeat visits to households to maintain the sample and we note this introduces the potential for selection bias into the results for Mexico. Secondly, the data for stroke and some risk factors were based on self-reports, which may lead to recall bias. However, validated symptom-reporting methods were also used in these analyses to estimate and compare prevalence rates for angina to improve prevalence estimates. Thirdly, the question on stroke in SAGE did not distinguish between ischemic stroke and hemorrhagic stroke. Last, these results are based on cross-sectional data and as such, cannot be sure of the direction of the associations we identified.

\section{Conclusions}

In conclusion, our study provided representative prevalence of angina and stroke and relevant risk factors in elders in six LIMCs. Due to the variation pattern of prevalence and risk factors distribution, policies and health interventions will need to be targeted and tailored for a broad range of local conditions to achieve the health goals set by the United Nations for 2025 .

\footnotetext{
Abbreviations

BMI: Body mass index; CVD: Cardiovascular disease; GBD: Global burden of disease; GNI: Gross national income; GPAQ: Global Physical Activity Questionnaire; HICs: High income countries; IHD: Ischemic heart disease; LMIC: Low- and middle- income countries; SAGE: Study on global AGEing and adult Health; SES: Social-economic status; WHO: World Health Organization
}

\section{Acknowledgements}

The authors would like to thank the respondents and interviewers from all six SAGE countries for their contributions and hard work. 


\section{Funding}

This work was supported by WHO, the US National Institutes on Aging through Interagency Agreements [OGHA 04034785; YA1323-08-CN-0020; Y1-AG-1005-01] and through a research grant (R01-AG034479), and Three-year Action Plan on Public Health, Phase IV, Shanghai, China[15GWZK0801;GWIV-22].

\section{Availability of data and materials}

The datasets supporting the conclusions of this article are available upon request in the website of WHO (http://apps.who.int/healthinfo/systems/ surveydata/index.php/catalog/sage).

\section{Authors' contributions}

FW, PK, YFG and YZ designed, implemented the conduct of this study. YR and YFG conceived of the analysis, and drafted the manuscript. YR, YFG, YS, ZZH, YZ and SYS contributed to the statistical analyses. ZZH and SYS contributed to the editing of initial draft. All authors read and approved the final manuscript.

\section{Ethics approval and consent to participate}

WHO's Ethical Review Committee approved SAGE (RPC146), and each country obtained local ethical approval to conduct the study. Written informed consent was obtained from each respondent.

\section{Competing interests}

The authors declare that they have no competing interests.

\section{Publisher's Note}

Springer Nature remains neutral with regard to jurisdictional claims in published maps and institutional affiliations.

\section{Author details}

'Shanghai Municipal Center for Disease Control and Prevention (Shanghai CDC), Shanghai, China. ${ }^{2}$ World Health Organization, Geneva, Switzerland. ${ }^{3}$ Research Institute for Health Sciences, Chiang Mai University, Chiang Mai, Thailand.

Received: 4 December 2017 Accepted: 1 June 2018

Published online: 20 June 2018

\section{References}

1. Roth GA, Johnson C, Abajobir A, Abd-Allah F, Abera SF, Abyu G, et al. Global regional, and national burden of cardiovascular diseases for 10 causes, 1990 to 2015. J Am College Cardiol. 2017;70(1):1-25.

2. Cardiovascular diseases (CVDs) Fact sheet. Available at: http://www.who.int/ en/news-room/fact-sheets/detail/cardiovascular-diseases-(cvds). Accessed 15 Mar 2017

3. World Health Organization. Burden: mortality, morbidity and risk factors. In: Alwan A, editor. Global Status Report on Noncommunicable Diseases 2010. Geneva: World Health Organization; 2011.

4. Gaziano TA, Bitton A, Anand S, Abrahams-Gessel S, Murphy A. Growing Epidemic of Coronary Heart Disease in Low- and Middle-Income Countries. Curr Probl Cardiol. 2010;35:72-115.

5. Yusuf S, Rangarajan S, Teo K, Islam S, Li W, Liu L, et al. Cardiovascular risk and events in 17 low-, middle-, and high-income countries. N Engl J Med. 2014;371:818-27

6. Teo KK, Dokainish $\mathrm{H}$. The Emerging Epidemic of Cardiovascular Risk Factors and Atherosclerotic Disease in Developing Countries. Can J Cardiol. 2017:33:358-65.

7. Prince MJ, Wu F, Guo Y, Gutierrez Robledo LM, O'Donnell M, Sullivan R, et al. The burden of disease in older people and implications for health policy and practice. Lancet. 2015;385:549-62.

8. Corsi DJ, Subramanian SV, Chow CK, et al. Prospective Urban Rural Epidemiology (PURE) study: Baseline characteristics of the household sample and comparative analyses with national data in 17 countries. American Heart Journal. 2013:166:636-46.

9. Kowal P, Chatterji S, Naidoo N, Biritwum R, Fan W, Lopez Ridaura R, et al. Data resource profile: the World Health Organization Study on global AGEing and adult health (SAGE). Int J Epidemiol. 2012;41:1639-49.

10. United Nations Educational Scientific and Cultural Organization. International Standard Classification of Education (ISCED). 1997. ISBN 929189-035-9. Available at: http://uis.unesco.org/sites/default/files/documents/ international-standard-classification-of-education-1997-en_0.pdf.
11. Ferguson BD, Tandon A, Gakidou E, Murray CJL. Estimating permanent income using asset and indicator variables. In: Evans DE, Murray CJL, editors. Health systems performance assessment debates, methods and empiricism. Geneva: World Health Organization; 2003. p. 747-60.

12. World Health Organization. Guidelines for controlling and monitoring the tobacco epidemic. Geneva: World Health Organization; 1998. p. 76-101.

13. World Health Organization. Global Physical Activity Questionnaire (GPAQ) Analysis Guide. Available at: http://www.who.int/chp/steps/resources/ GPAQ_Analysis_Guide.pdf?ua=1,2017-08-08. Accessed 15 Mar 2017.

14. World Health Organization. Diet, nutrition and the prevention of chronic diseases. Report of a joint WHO/FAO expert consultation. In: WHO Technical Report Series No 916. Geneva: World Health Organization; 2003.

15. World Health Organization. Obesity: preventing and managing the global epidemic. In: WHO Technical Report Series 894. Geneva: World Health Organization; 2000.

16. Consultation WE. Appropriate body-mass index for Asian populations and its implications for policy and intervention strategies. Lancet. 2004; 363:157-63

17. Ahmad OB, Boschi Pinto C, D. Lopez A, Jl Murray C, Lozano R, Inoue M. Age Standardization of Rates: A New WHO Standard, vol. No. 31; 2001

18. He W, Muenchrath MN, Kowal P, U.S. Census Bureau. Shades of Gray: A Cross-Country Study of Health and Well-Being of the Older Populations in SAGE Countries, 2007-2010. Washington, DC: U.S. Government Printing Office; 2012

19. Roth GA, Huffman MD, Moran AE, Feigin V, Mensah GA, Naghavi M, et al. Global and regional patterns in cardiovascular mortality from 1990 to 2013. Circulation. 2015;132:1667-78.

20. GBD 2016 Causes of Death Collaborators. Global, Regional, and National Age-Sex Specific Mortality for 264 Causes of Death, 1980-2016: A Systematic Analysis for the Global Burden of Disease Study 2016. Lancet. 2017;390(10100):1151-210

21. Omran AR. The epidemiologic transition: a theory of the epidemiology of population change. Milbank Mem Fund Q. 1971;49:509-38.

22. Yusuf S, Hawken S, Ounpuu S, Dans T, Avezum A, Lanas F, et al. Effect of potentially modifiable risk factors associated with myocardial infarction in 52 countries (the INTERHEART study): case-control study. Lancet. 2004;364: 937-52

23. O'Donnell MJ, Xavier D, Liu L, Zhang H, Chin SL, Rao-Melacini P, Rangarajan $\mathrm{S}$, et al. Risk factors for ischaemic and intracerebral haemorrhagic stroke in 22 countries (the INTERSTROKE study.): a case-control study. Lancet. 2010; 376:112-23.

24. Danaei G, Finucane MM, Lin JK, Singh GM, Paciorek CJ, Cowan MJ, et al. National, regional, and global trends in systolic blood pressure since 1980: systematic analysis of health examination surveys and epidemiological studies with 786 country-years and 5.4 million participants. Lancet. 2011;377: 568-77

25. Ettehad D, Emdin CA, Kiran A, Anderson SG, Callender T, Emberson J, et al. Blood pressure lowering for prevention of cardiovascular disease and death: a systematic review and meta-analysis. Lancet. 2016; 387(10022):957-67.

26. Lloyd-Sherlock P, Beard J, Minicuci N, Ebrahim S, Chatterii S. Hypertension among older adults in low- and middle-income countries: prevalence, awareness and control. Int J Epidemiol. 2014:43:116-28.

27. Roberts B, Stickley A, Balabanova D, Haerpfer C, McKee M. The persistence of irregular treatment of hypertension in the former Soviet Union. J Epidemiol Community Health. 2012;66:1079-82.

28. Su $C$, Huang $H$, Wang $H J$, Wang $Z H$, Zhang JG, Du WW, et al. Study on status and trend of physical activity among Chinese adults aged 18-49 years old in 9 provinces from 1997 to 2009. Chin J Health Educ. 2013. 186:5926-32.

29. Li Y, Wang DD, Ley SH, Howard AG, He Y, Lu Y, et al. Potential impact of time trend of life-style factors on cardiovascular disease burden in China. J Am Coll Cardiol. 2016;68:818-33.

30. NCD Risk Factor Collaboration (NCD-RisC). Trends in adult body-mass index in 200 countries from 1975 to 2014: a pooled analysis of 1698 populationbased measurement studies with 19.2 million participants. Lancet. 2016:387 1377-96.

31. Ng M, Fleming T, Robinson M, Thomson B, Graetz N, Margono C, et al. Global, regional, and national prevalence of overweight and obesity in children and adults during 1980-2013: a systematic analysis for the Global Burden of Disease Study 2013. Lancet. 2014;384:766-81. 
32. Ma J, Cai XH, Wang HJ, Dong B, Song Y, Hu PJ, et al. The trend analysis of overweight and obesity in Chinese students during 1985-2010. Chin J Prev Med. 2012:46:776-80.

33. Hall JN, Moore S, Harper SB, Lynch JW. Global variability in fruit and vegetable consumption. Am J Prev Med. 2009;36:402-9.

34. Wu F, Guo Y, Chatterii S, Zheng Y, Naidoo N, Jiang Y, et al. Common risk factors for chronic non-communicable diseases among older adults in China, Ghana, Mexico, India, Russia and South Africa: the study on global AGEing and adult health (SAGE) wave 1. BMC Public Health. 2015; https:// doi.org/10.1186/s12889-015-1407-0.

35. Patel V, Chatterii S, Chisholm D, Ebrahim S, Gopalakrishna G, Mathers C, et al. Chronic diseases and injuries in India. Lancet. 2011;377:413-28.

36. Institute of Health Metrics and Evaluation. GBD Compare 2010. Available at: http://vizhub.healthdata.org/gbd-compare/. Accessed 30 Apr 2017.

37. Giovino GA, Mirza SA, Samet JM, Gupta PC, Jarvis MJ, Bhala N, et al. Tobacco use in 3 billion individuals from 16 countries: an analysis of nationally representative cross-sectional household surveys. Lancet. 2012;380:668-79.

38. Bhan N, Srivastava S, Agrawal S, Subramanyam M, Millett C, Selvaraj S, et al. Are socioeconomic disparities in tobacco consumption increasing in India? A repeated cross-sectional multilevel analysis. BMJ Open. 2012. https://doi. org/10.1136/bmjopen-2012-001348.

39. Fernández-Solà J. Cardiovascular risks and benefits of moderate and heavy alcohol consumption. Nat Rev Cardiol. 2015;12:576-87.

40. Roerecke M, Rehm J. Alcohol consumption, drinking patterns, and ischemic heart disease: a narrative review of meta-analyses and a systematic review and meta-analysis of the impact of heavy drinking occasions on risk for moderate drinkers. BMC Med. 2014;12:182.

41. Britton A, McKee M. The relation between alcohol and cardiovascular disease in Eastern Europe: explaining the paradox. J Epidemiol Community Health. 2000;54:328-32.

42. Leong DP, Smyth A, Teo KK, McKee M, Rangarajan S, Pais P, et al. Patterns of alcohol consumption and myocardial infarction risk: observations from 52 countries in the INTERHEART case control study. Circulation. 2014;130:390-8.

43. Bell S, Daskalopoulou M, Rapsomaniki E, George J, Britton A, Bobak M, et al. Association between clinically recorded alcohol consumption and initial presentation of 12 cardiovascular diseases: population based cohort study using linked health records. BMJ. 2017. https://doi.org/10.1136/bmj.j909.

\section{Ready to submit your research? Choose BMC and benefit from:}

- fast, convenient online submission

- thorough peer review by experienced researchers in your field

- rapid publication on acceptance

- support for research data, including large and complex data types

- gold Open Access which fosters wider collaboration and increased citations

- maximum visibility for your research: over $100 \mathrm{M}$ website views per year

At BMC, research is always in progress.

Learn more biomedcentral.com/submissions 